\title{
In-silico analysis: common biomarkers of NDs
}

\author{
Deepanjan Sarkar,Souvik Chakraborty,Sushmita Bhowmick, Tarasankar Maiti \\ Department of Physiology, Bhairab Ganguly College \\ Department of Physiology, West Bengal State University.
}

\begin{abstract}
Neurodegenerative disorders (NDs) are a class of rapidly rising devastating diseases and the reason behind are might be an improper function of related genes or a mutation in a particular gene or even could be autoimmune also. Parkinson's disease (PD), Multiple sclerosis (MS), Huntington's disease (HD) are some of the NDs, and still, incurable fully. Apart from the similarities in symptoms, there are common genes that express somehow a differential manner in patients of PDs, MSs, and HDs. A total of 1197 differentially expressed genes (DEGs) are obtained by analyzing the chosen datasets. The protein interactions by STRING online tool and degree sorted hubs obtained through a plug-in in Cytoscape; Cyto-Hubba. Among the sorted hubs KRAS, CREB1, PIK3CA, JAK2 are the ones that are not only common to all the studied datasets of NDs but also in other neurological disorders like Alzheimer's. The enriched pathways with biological process, molecular function, cellular component, and KEGG pathway details are obtained and analyzed using Enricher. This paper frames that the obtained hub genes could be potential biomarkers also and a need for further drug design for finding a possible cure.
\end{abstract}

Keywords: Differentially expressed genes; Enriched pathway; Hub gene; Potential biomarker.

\section{Introduction}

In today's world, neurological disorders are the utmost problem as they grasp a large group of people, especially aged people. Approximately a total of 1 billion around the world i.e. every one in six people is dealing with those diseases. The impairment in the function of the ANS and PNS is due to degeneration of neurons, sporadic or even hereditary (Magalingam et al., 2018) in some cases, further leads to normal physiological activities, thinking criteria, and mental health. Though there are so many which belong to this category, Parkinson's disease, Multiple sclerosis, Huntington's disease are the major ones holding the severity of that class. There's a severe loss in dopamine neurotransmitter releasing neurons(Kouli et al., 2018) from the harsh region of our brain; substantia nigra in Parkinson's disease patients. Symptoms that are faced by the group of patients are dizziness, fatigue, development of muscle stiffness, frequent nightmares, anxiety, disability in speaking, and many more. The proper cause is still unidentified, but antigen-presenting cells along with CD4+ cells and Killer T cells assist in Multiple sclerosis(Ghasemi et al., 2017), and even the factors could be environmental also. With cognitive problems the suffers also face low vision power, spasms, weakness, impotence, etc. Huntington's disease is somehow classical, defect in the base pairs of HTT gene (Nopoulos, 2016) leads to abnormal functioning of the Huntingtin protein; necessary for normal brain development. Compulsive behavior, depression, hallucination, anxiety, slowness, mood swings, muscle spasms are fallen under its symptoms. 
bioRxiv preprint doi: https://doi.org/10.1101/2021.09.25.461779; this version posted September 27, 2021. The copyright holder for this preprint (which was not certified by peer review) is the author/funder, who has granted bioRxiv a license to display the preprint in perpetuity. It is made available under aCC-BY-ND 4.0 International license.

In this study, we analyzed Parkinson's disease dataset (GSE19587); the Multiple sclerosis disease dataset (GSE38010), and Huntington's disease dataset (GSE1767) to find out the common drug target and treatment of the neurodegenerative disorders.

\section{Materials and Methods}

\subsection{Data set for study}

Gene expression omnibus (https://www.ncbi.nlm.nih.gov/geo/) is a fully publicly accessible data repository containing high throughput data, array data, sequence-based data, and so on. Using keywords or disease names, GEO accession number, and even with author name as a search input GEO datasets in the database can find out. By putting the disease name as search input we select the GSE19587 dataset associated with Parkinson's disease. 22 tissue samples using HG-U133A_2 Affymetrix chip array are used among which tests are 12 (6 dorsal motor nucleus and 6 inferior olivary nucleus) and samples are 10 (5 dorsal motor nucleus of vagus and 5 are inferior olivary nucleus). In multiple sclerosis, the GSE38010 dataset is selected which did with the help of 7 histologically identified MS cells. This dataset containing 5 tests (including 1 early-stage active inflammation, 2 chronic active plaque following demyelination active inflammation, and 2 chronic plaque after inflammation has subsided -late-stage) and 2 white matter from age-matched healthy control species. GSE1767 dataset that containing 26 sample species is chosen for Huntington's disease is associated with the blood markers for this disease. From that total of 12 test samples are selected and 14 normal samples are chosen. There was no human experiment performed and all the data used for this study are available in online NCBI.

\begin{tabular}{|l|l|l|l|l|}
\hline Disease & $\begin{array}{l}\text { GEO accession } \\
\text { number }\end{array}$ & $\begin{array}{l}\text { Total number of } \\
\text { samples }\end{array}$ & $\begin{array}{l}\text { Diseased } \\
\text { samples/ Test } \\
\text { species }\end{array}$ & $\begin{array}{l}\text { Healthy samples/ } \\
\text { Control species }\end{array}$ \\
\hline $\begin{array}{l}\text { Parkinson's } \\
\text { Disease }\end{array}$ & GSE19587 & 22 & 12 & 10 \\
\hline $\begin{array}{l}\text { Multiple } \\
\text { Sclerosis }\end{array}$ & GSE38010 & 7 & 5 & 2 \\
\hline $\begin{array}{l}\text { Huntington's } \\
\text { Disease }\end{array}$ & GSE1767 & 26 & 12 & 14 \\
\hline
\end{tabular}

Table: 1- test and sample information of datasets for this study, obtained from GEO; NCBI

\subsection{Data processing and analysis}

All the samples are selected as tests and controls and a web-based tool GEO2R

(https://www.ncbi.nlm.nih.gov/geo/geo2r/) is used to identify all the differentially expressed genes by comparing those two selected groups of the GEO series of GSE19587, GSE38010, GSE1767. The GEO2R tool used another two Bioconductor.R packages namely GEOquary and Limma respectively for the processing of those data (Clough \& Barrett, 2016). After processing with the GEO2R tool in each set of datasets, thousands of several differentially expressed genes were obtained in a text file format based on test vs control species. The obtained file format contains different groups namely Gene ID, adjusted p-value, p-value, t-value, b-value, Log-FC, gene symbol, and gene title respectively. 
bioRxiv preprint doi: https://doi.org/10.1101/2021.09.25.461779; this version posted September 27, 2021. The copyright holder for this preprint (which was not certified by peer review) is the author/funder, who has granted bioRxiv a license to display the preprint in perpetuity. It is made available under aCC-BY-ND 4.0 International license.

a)

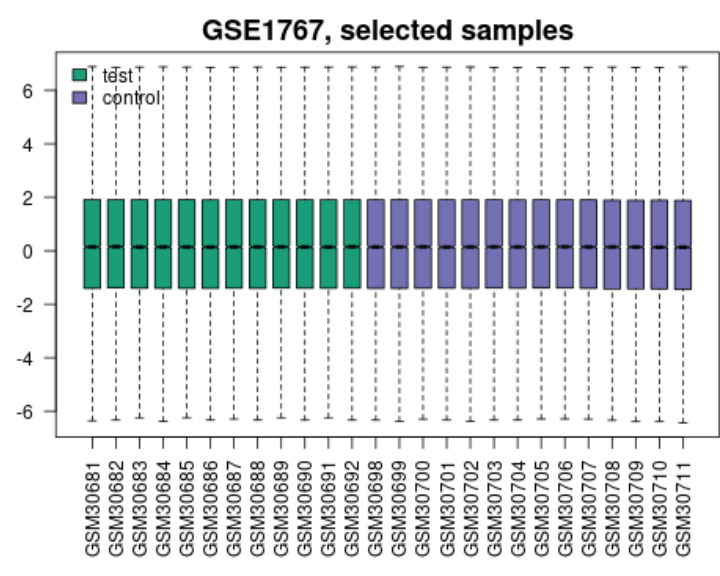

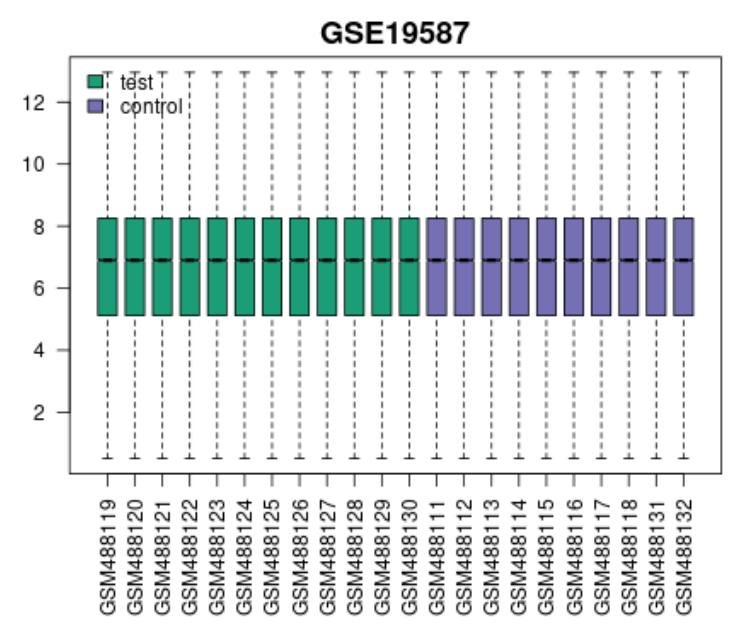

b)

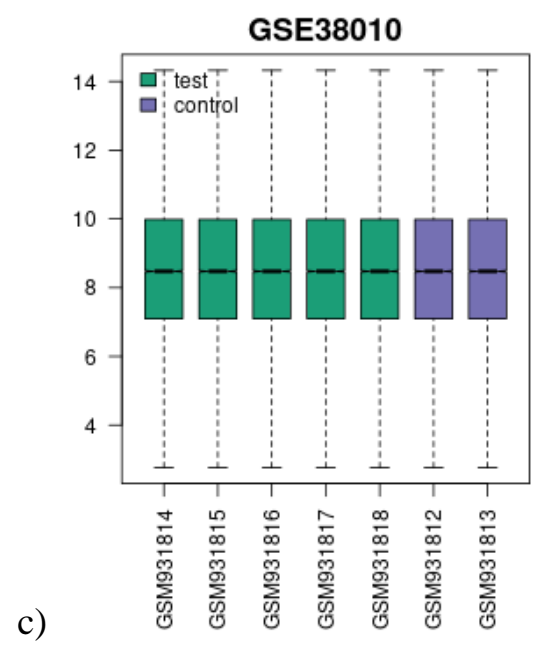

Fig:1; Box plots of (a) Huntington's disease (GSE1767), (b) Parkinson's disease(GSE19587), (c) Multiple sclerosis (GSE38010) gene expression datasets. This distribution of test vs control has been shown after data normalization with the GEO2R tool.

\subsection{Selection of Differentially expressed genes and processing}

After downloading all the DEG lists, import those in different excel sheets to perform some basic works. Firstly all the DEGs are sorted by the ascending order of P-values and the DEGs $\leq 0.05$ in P-value are selected for further processing. A P-value below 0.05 is significant and it describes that there is only a 5\% chance that the null hypothesis is correct or the results are random (Nahm, 2017). Now all the selected DEGs are further processed based on Log-FC criteria, where the genes with LogFC $\geq 0.5$ are selected for this study. Log-FC explains the fold change i.e. if there is a Log-FC of value 1 that means this particular gene is twice much expressed in the diseased case as compared to a healthy one (Farztdinov \& McDyer, 2012). No negative values of Log-FC are considered which means this study is based on the overexpressed or upregulated genes only. 
bioRxiv preprint doi: https://doi.org/10.1101/2021.09.25.461779; this version posted September 27, 2021. The copyright holder for this preprint (which was not certified by peer review) is the author/funder, who has granted bioRxiv a license to display the preprint in perpetuity. It is made available under aCC-BY-ND 4.0 International license.

$P$ a g e | 4

\subsection{Identification of common genes and DEGs}

All the genes that match the above criteria are selected and paste alternatively as input in a computer software named Funrich (http://www.funrich.org/) (Pathan et al., 2015). As a result, we obtained all the common genes in the three studied datasets GSE19587, GSE38010, GSE1767, and DEGs on the same side. This data is beautifully showed as a Venn diagram by using that Fumrich tool.

\subsection{Network analysis of differentially expressed genes}

All the COMMON DEGs obtained using funrich are further selected and imported in an online web-based tool String (https://string-db.org/) in search of network analysis. The string is an online database that helps to find out the interactions among your proteins of interest, to do so; the string uses further main five sources named genomic context prediction, high throughput lab experiments, coexpression, automated textmining, and the previous knowledge stored in this database. Providing DEGs as input, the reference organism is set to Homo sapience for obtaining the proteinprotein interactions a network is obtained with a confidence score of 0.150 (von Mering et al., 2003). Finally, the network is sorted by the K-means algorithm clustering method (Lei et al., 2017) and exported in a high-resolution jpeg format.

\subsection{Hub identification of common DEGs}

The resultant network obtained from the string online tool is then imported into .csv format into a desktop-based software tool Cytoscape. It's an open-source platform through which the molecular interactions and all the biological pathways can be visualized and further can be integrated with gene expression profiles and annotations (Kohl et al., 2011). All of it provides a basic feature for data visualization, analysis, and integration. The network file which is generated using string is then directly imported into Cytoscape software. Now for finding the top hub genes (genes with maximum nodes and edges indicating maximum connection with others) from this network a plug-in of this software Cyto-Hubba is used. A top twenty-degree sorted network is then generated separately with proper color indication.

\subsection{Enrichment analysis and miRNA interactions}

Now for further study, it's complementary to see the pathways that are upregulated regarding these DEGs. To do so, a web-based tool Enricher(https://maayanlab.cloud/Enrichr/) is in use. All the obtained DEGs are provided as an input and then analyzed to visualize the diagrammatic representation of enriched KEGG pathways and Gene Ontology function(GO) that consists of Biological processes, Molecular functions, and Cellular components (Enrichr: A Comprehensive Gene Set Enrichment Analysis Web Server 2016 Update, n.d.). Along with this, the interaction between all the DEGs and functional microRNAs is obtained through an online web software miRNet. The highly connected node or the maximum interaction is considered as a hub here.

\section{Result interpretation}

Using microarray data all the differentially expressed genes are obtained for this study. All the interactive networks, biological pathways, molecular and cellular functions, miRNA interactions 
bioRxiv preprint doi: https://doi org/10.1101/2021.09.25.461779; this version posted September 27, 2021. The copyright holder for this preprint (which was not certified by peer review) is the author/funder, who has granted bioRxiv a license to display the preprint in perpetuity. It is made available under aCC-BY-ND 4.0 International license.

are generated for the study of these three neurodegenerative disorder datasets, Parkinson's disease, Multiple sclerosis, Huntington's disease.

\subsection{Identification of DEGs}

P-value $\leq 0.05$ and $\operatorname{LogFC} \geq 0.5$ are set as basic criteria for the selection of the genes as an input. So by considering this limit a total of 2883 genes out of 22277 in Parkinson's disease (GSE19587), 4033 genes out of 33398 in Multiple sclerosis (GSE38010), and 3385 genes out of 17674 in Huntington's disease (GSE1767) are selected for further analysis. All the data are obtained from NCBI are previously normalized. Among these all, 2299 DEGs in PD, 2848 DEGs in MS and, 2822 DEGs in HD are identified.

\subsection{Common DEGs analysis}

By performing the Venn diagram a total of 106 genes are obtained that are common in all three studied datasets of NDs, 543 DEGs are common in between HD and MS, 264 DEGs are common in PD and HD and, 284 DEGs are common among HD and MS.

GeneMania is used to draw the interactions among the identified DEGs that are common in all. The generated network represents the various parameters of interaction such as co-expression having a score of $72 \cdot 98 \%$ (shown in light purple color), genetic interactions of $9 \cdot 87 \%$ (in light green color), physical interactions of $8.75 \%$ (here in pink color), co-localization of $3.49 \%$ (presented as bluish), and others not in a significant manner. By using the genomic and proteomic databases geneMania identifies similar genes with the input list and draws a network (Warde-Farley et al., 2010).

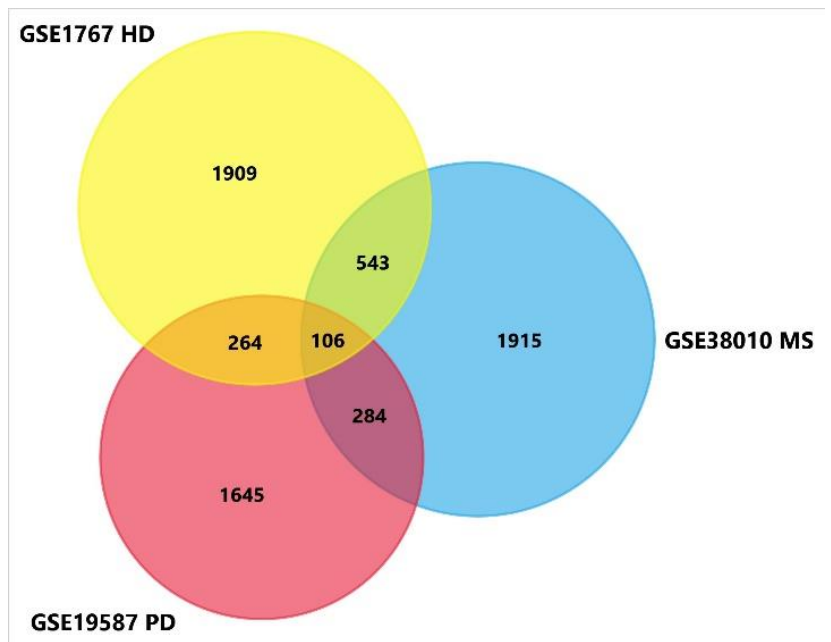

Fig:2; Venn diagram represents the common and uncommon genes in the datasets of PD, MS, and HD. Total 106 genes are common in all three datasets.

\subsection{Common DEGs network}

\subsubsection{Protein-protein interaction}


bioRxiv preprint doi: https://doi.org/10.1101/2021.09.25.461779; this version posted September 27, 2021. The copyright holder for this preprint (which was not certified by peer review) is the author/funder, who has granted bioRxiv a license to display the preprint in perpetuity. It is made available under aCC-BY-ND 4.0 International license.

Pag e $\mid 6$

All the common 106 DEGs regarding these disorders are imported into the string to find the related protein-protein interactions. In the obtained result some proteins are showing maximum connectivity with others that means a node with a greater number of edges and some of them are showing low connectivity. KRAS, CREB1, PIK3CA, JAK2, ATR are some of them showing high and significant interactions with others. K-means clustering is shown in the network provided by the String. The network is clustered into 3 different cluster groups with centrally placed prominent nodes like KRAS, JAK2, PIK3CA, and some others. This network contains a total of 106 nodes, 477 edges. This network has an average degree of a node is 9 and a clustering coefficient of 0.329 and this network has significantly more interactions. String also provides gene ontologies with proper strength value and false discovery rate.

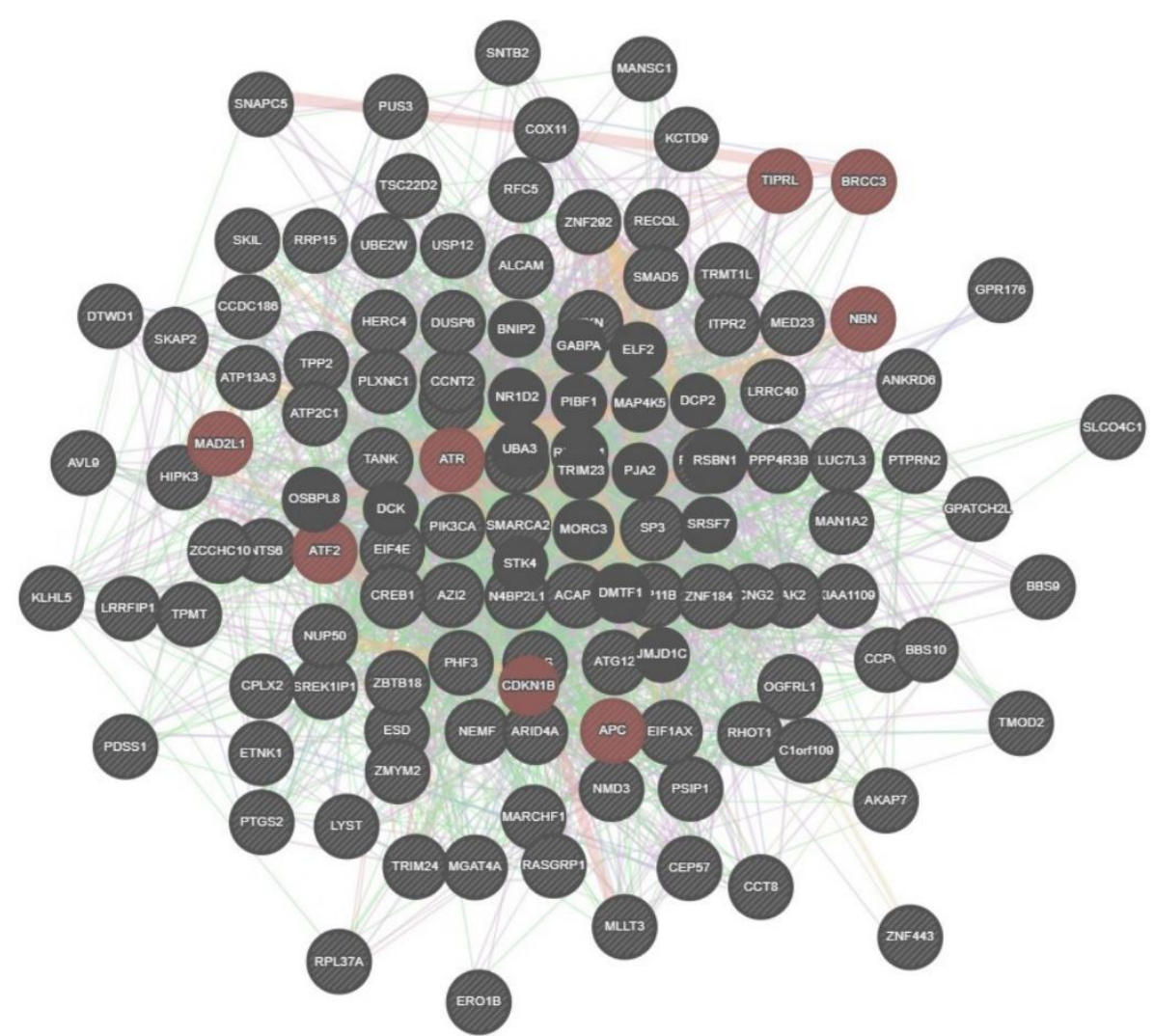
Networks
Co-expression
Genetic Interactions
Physical Interactions
Predicted
Co-localization
Pathway
Shared protein domains

Functions

- cell cycle checkpoint

Fig:3; common networks between DEGs of PD, MS, HD. Shows all the connections among those DEGs with different color representation; co-expression having a score of $72.98 \%$ (shown in light purple color), genetic interactions of $9 \cdot 87 \%$ (in light green color), physical interactions of $8.75 \%$ (here in pink color), co-localization of $3 \cdot 49 \%$ (presented as bluish).

\subsubsection{Hub gene analysis}


bioRxiv preprint doi: https://doi.org/10.1101/2021.09.25.461779; this version posted September 27, 2021. The copyright holder for this preprint (which was not certified by peer review) is the author/funder, who has granted bioRxiv a license to display the preprint in perpetuity. It is made available under aCC-BY-ND 4.0 International license.

P a g e $\mid 7$

The network obtained from the string s then directly sends into Cytoscape or the common DEGs input into Cytoscape separately. Using cytohubba top 20 DEGs rank is generated based on maximum interactions with neighbors. Degree centrality is chosen as the criteria in hub identification in cytohubba. The top identified hub genes are KRAS, PIK3CA, JAK2, ATR, NCOR1, EIF4E, SMARCA2, MAD2L1, NMD3, CREB1, ARID4A, RECQL, TXN, PTGS4, ATF2, BBS10, DUSP6, MED23, BRCC3, SMAD5 and the degree of these hubs are 45, 41, 27, 25, 23, 22, 21, 21, 20, 20, 18, $18,17,16,16,16,16,16,15,14$ respectively. Among those hub genes; PIK3CA, KRAS, JAK2, CREB1 are very common in all neurodegenerative disorders and cancer. KRAS shows the highest interaction whereas SMAD5 is the least connected node among these top 20 hub genes. Besides measuring the degree centrality, the other parameters such as Betweenness, Bottle-neck, Closeness, Clustering coefficient, DNMC, EcCentrality, MCC, EPC, MNC, Radiality, Stress also are measured. For this study, degree centrality is primarily focused on achieving the most connected nodes.

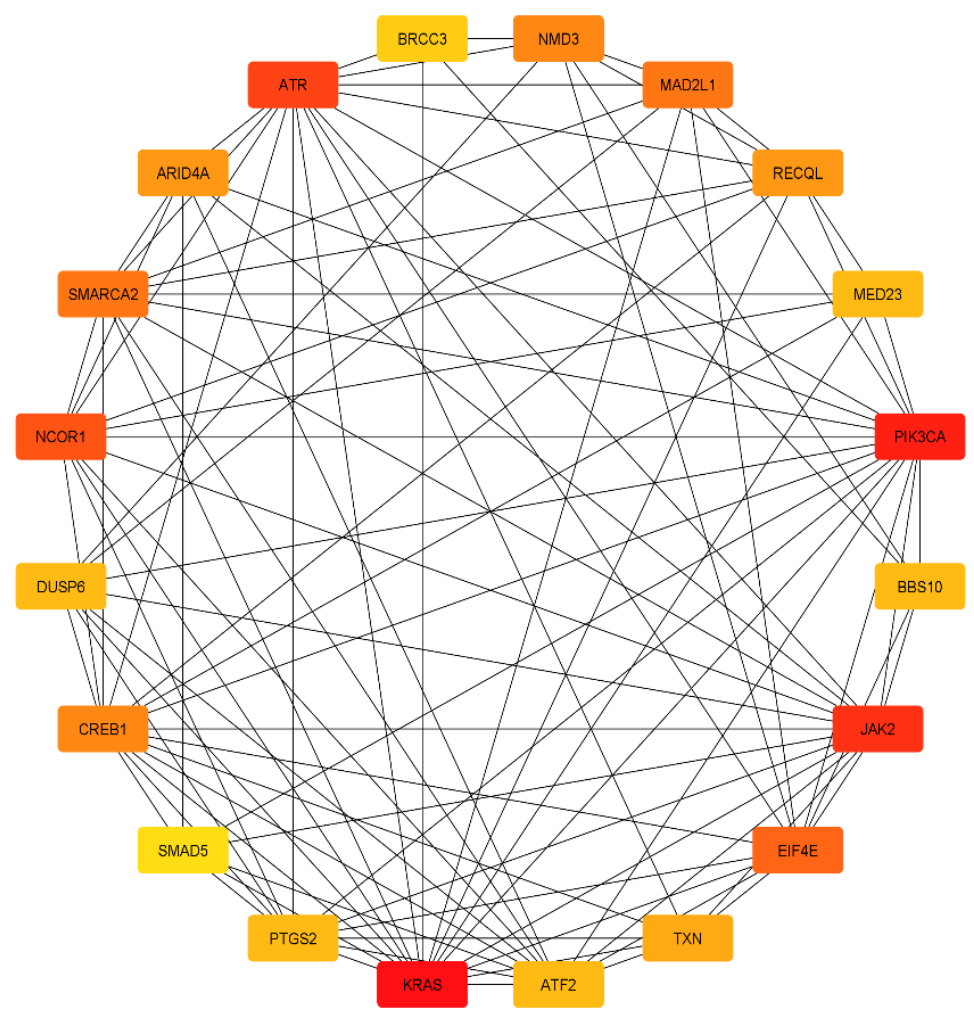

Fig: Hub genes from the common DEGs identified through cytohubba plugin, KRAS has the maximum connectivity and degree of centrality of 45

\subsubsection{DEGs and miRNA's interaction network}

The interaction between the common DEGs and their related miRNAs is obtained from the miRNet database. A total of 7418 miRNAs are found related to the common DEGs of all three disorders PD, MS. HD. The large size of the node indicated higher connectivity. Here genes are yellow in color, miRNAs are blue in color whereas transcription factors are shown with green color. The network clearly shows that the gene ZBTB18 is hub here and has a degree of centrality 267. TSC22D2 has a slightly lower degree of centrality as compare to ZBTB18 of 240 and ETNK1 of 218. 
bioRxiv preprint doi: https://doi.org/10.1101/2021.09.25.461779; this version posted September 27, 2021. The copyright holder for this preprint (which was not certified by peer review) is the author/funder, who has granted bioRxiv a license to display the preprint in perpetuity. It is made available under aCC-BY-ND 4.0 International license.

Whereas has-let-71f1 and has-let-7a3b both having a lower degree of centrality of 1 . The degree centrality of all the nodes and other information regarding this is provided in a table.

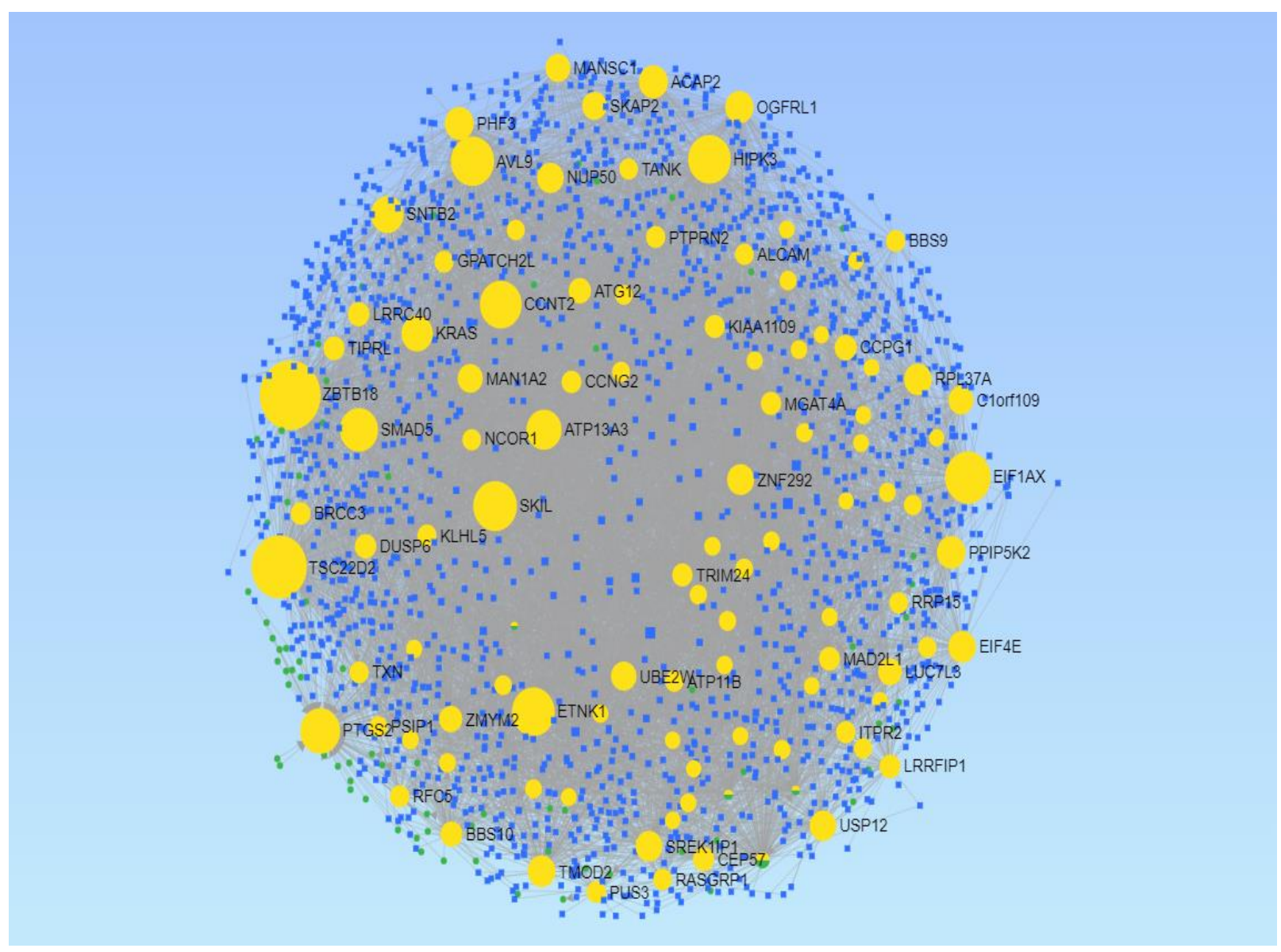

Fig:4; interaction between miRNA and 106 common genes of PD, MS, HD obtained via miRNet. ZBTB18 is identified as a hub here as it has a degree of centrality of 267.

\subsection{GO processes and KEGG pathways}

Through enricher, the Gene Ontology (GO) i.e Biological processes, Molecular functions, Cellular components, and KEGG pathways related to all common DEGs are obtained. Some of these details are also obtained using String. A total of $871 \mathrm{GO}$ terms are significantly enriched in the case of biological processes. In them, retinal ganglionic cell axon guidance(GO:0031290) has a combined score value of 131.13 with the involvement of gene ALCAM, positive regulation of synaptic plasticity with a score of 104 involving gene CPLX2. 158 total GO terms are identified that belong to molecular functions. Among them, PIK3CA is involved with phosphatidylinositol 3 kinase activity with a score of 47.92 and has an odds ratio of 17.21 (GO:0035004)another gene RECQ1 with a combined score of 31.64 and an odds ratio of 12.62 involved in $3^{\prime}-5$ ' DNA helicase activity. A total of 115 GO terms are significantly enriched in GO of cellular components and npBAF complex (GO:0071564) having the score of 54.32 with gene SMARCA2 enriched. Another cellular component is azurophil granule (GO:0042582) also expressed the enriched DEGs GLIPR1, SLCO4C1, ATP11B, CCT8. It also claimed that a total of 4 major KEGG pathways are significantly enriched. 6 genes in each case of cellular senescence, signaling pathway regulating pluripotency of stem cells, growth hormone synthesis and secretion and action are enriched and 5 in cholinergic synapse enriched. Overall these 
bioRxiv preprint doi: https://doi.org/10.1101/2021.09.25.461779; this version posted September 27, 2021. The copyright holder for this preprint (which was not certified by peer review) is the author/funder, who has granted bioRxiv a license to display the preprint in perpetuity. It is made available under aCC-BY-ND 4.0 International license.

DEGs are associated with a variety of biological pathways, molecular functions that are relevant to neuronal growth, brain development and differentiation, and homeostasis. Significantly 51 genes are enriched in brain tissue (BTO:0000142) present in the network. 74 DEGs are showing alternative splicing, 67 are phosphoprotein, 27 are associated with ubiquitin conjugation.

\section{Discussion}

The datasets of PD, MS, HD are used for the aim to find potential similarities in terms of gene regulation, common DEGs with microRNAs, and enriched biological and cellular pathways among those neurodegenerative disorders. Extensive application of bioinformatics is required for analyzing gene expression profiles.

\subsection{Detailed network analysis}

By analyzing PPI interactions and hub analyzing using string and Cytoscape some of the genes KRAS, PIK3CA, JAK2 is shown in extensive regulation. KRAS, another GTPase hub ras protein bind to GTP/GDP and possess intrinsic GTPase activity. This gene plays an important role in cell proliferation and helps to promote tumors by silencing the tumor suppressor gene in colorectal cancer cells. Researchers have already shown that dysregulated RAS signaling can cause PA and specifically the astrocyte-specific expression of endogenous oncogenic KRAS (M.-J. Ryu et al., 2012). KRAS is associated with the regulation of synaptic plasticity (Stornetta \& Zhu, 2011). KRAS is also linked with stress conditions (Ghaddar et al., 2021) and modulates the chemical synaptic transmission (H.-H. Ryu et al., 2020), and also helps in neurogenesis (Bender et al., 2015). It controls the survival of the neuronal cells also (Fivaz \& Meyer, 2005). Phosphatidylinositol ,5-bisphosphate 3kinase is a $110 \mathrm{kDa}$ catalytic subunit having alpha PI3K that phosp[horylates PtdIns (phosphoinositide), PtdIns4p (Phosphatidylinopsito 4-phosphate), PtdIns (4,5)P2 to generate phosphatidylinositol 3,4,5-triphosphate(PIP3). PIP3 plays a key role by recruiting PH-domaincontaining protein to the membrane, including AKT and PDPK1, activating signaling cascades involved in cell growth, proliferation, survival, motility, and morphology. Disruption in the signaling pathways mediated by AKT and Erk in the association with PIK3CA leads to the pathogenesis of neurological disorders such as Parkinson's Alzheimers, Huntington's, and many others (Rai et al., 2019). The functions and regulatory mechanism of PI3K/AKT/mTOR signalling pathways are important in many human diseases including human brain disorders, neurodegenerative disorders, and tumors (Xu et al., 2020) (王梦华, 卢均坤. PI3K/Akt 信号通路及其抑制剂的研究进展 $[J]$. 医学信息, 2018, 031(010):34-36. Doi: CNKI:SUN:YXXX.0.2018-10-011. [Wang MH and Lu JK. Research Progress of PI3K/Akt Signaling Pathway and Its Inhibitors. Med Inf 2018;31(10): 34-36.], n.d.). Tyrosine-protein kinase JAK2 is a non-receptor tyrosine kinase involved in various processes such a development, cell growth, differentiation, or histone modifications. It mediates essential signaling events in both adaptive and innate immunity (Romano et al., 2017). In the cytoplasm, JAK2 plays a pivotal role in signaling transduction via association with type I receptors such as growth hormone(GHR), prolactin (PRLR), leptin(LEPR), erythropoietin(EPOR), thrombopoietin(THOP); or type II receptors including IFN-alpha, IFN-beta, IFN-gamma and multiple interleukins (Seif et al., 2017). JAK2 was identified as the first molecular marker of neurological disorders (Billot et al., 2011). JAK2 along with STAT3 activation contributes to neuronal damage following transient focal ischemia (Satriotomo et al., 2006). A mutation in Janus kinase is also associated with embolic stroke (Trifan et al., 2018). There is also some report that JAK2 is associated with cerebral venomous thrombosis; myelofibrosis (Jin et al., 2020). Another study reports that Salvianolic acid cerebral angiogenesis along with JAK2 ( $\mathrm{Li}$ et al., 2017). A recent study proves that the JAK2 tyrosine kinase is the key regulator of inactive synapse elimination (Yasuda et al., 2021). 


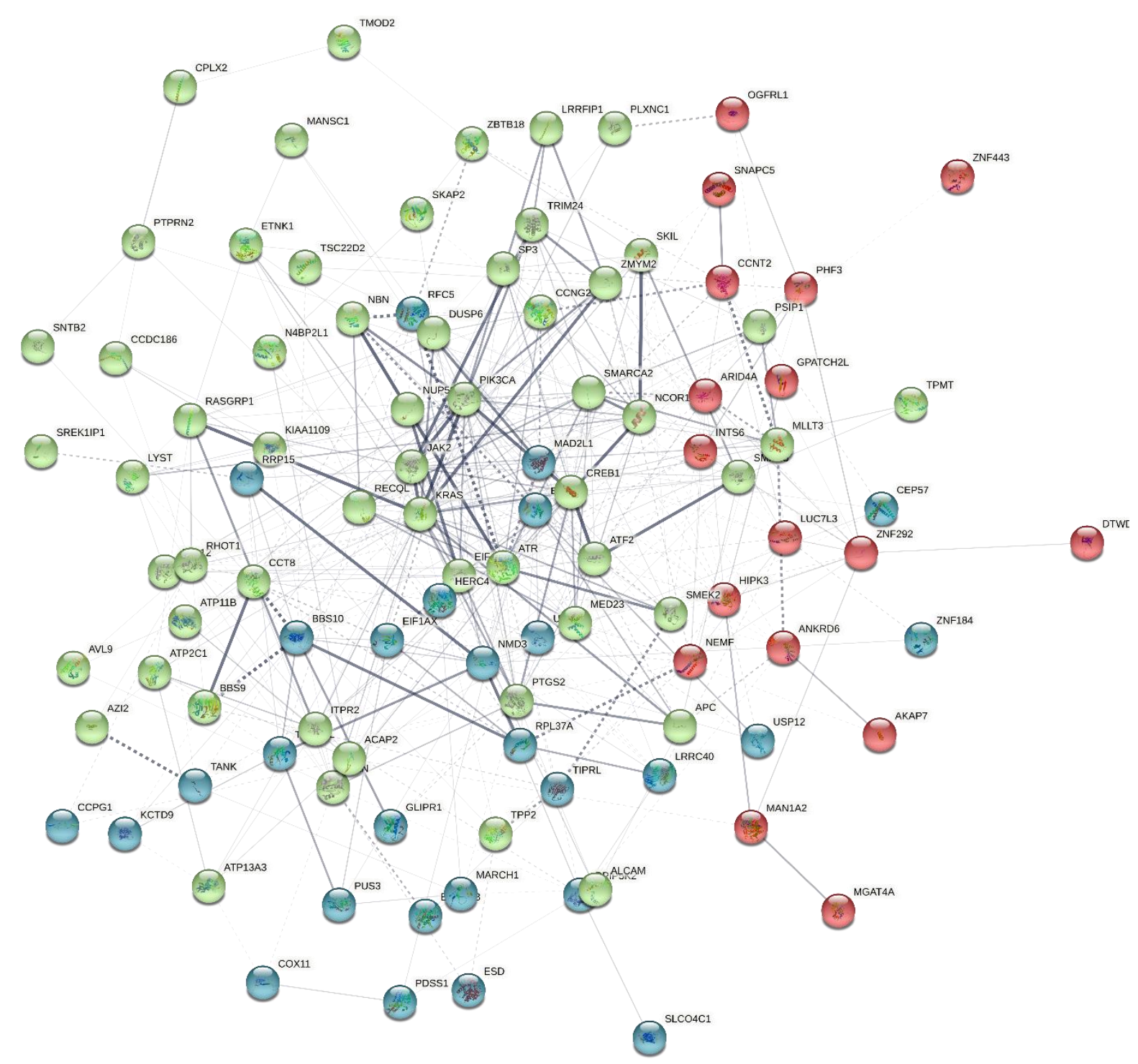

Fig:5; K-means clustering applied in PPI network of all common DEGs of PD, MS, HD. 3 cluster groups are present here. KRAS, PIK3CA, and JAK2 are the maximum connected nodes.

\subsection{Process and pathways analysis}

A wide range of vital processes such as homeostasis, brain, and nervous tissue development and differentiation are some of enriched GO associated with all the common DEGs. GO analysis using enricher showed that the enriched GO biological pathways are positive regulation of mitochondrial membrane permeability involved in the apoptotic process with a $\mathrm{p}$-value and combined score of 0.0009777 and 378.63 respectively and in association with gene ATF2 and RHOT1, betacatenin destruction complex assembly(GO:1904885) with a score and gene association of 172.43 and APC, regulation of C-terminal protein lipidation and fever generation and growth hormone receptor signaling with guanyl-nucleotide exchange factor activity. It also regulates the development of the heart and rescues a stalled ribosome (GO:0072344). Positive regulation of Golgi to plasma membrane protein transport and heat generation processes also enriched. Enriched GO for molecular functions are DNA binding transcription factor binding, cAMP response element-binding protein, ribosomal large subunit binding, acetylation-dependent protein binding, lysine-acetylated histone binding, protein kinase regulatory activity, RNA polymerase II specific DNA binding transcription factor 
bioRxiv preprint doi: https://doi.org/10.1101/2021.09.25.461779; this version posted September 27, 2021. The copyright holder for this preprint (which was not certified by peer review) is the author/funder, who has granted bioRxiv a license to display the preprint in perpetuity. It is made available under aCC-BY-ND 4.0 International license.

binding, thiol-dependent deubiquitinase, active in transmembrane transporter activity and deubiquitinase activity and many others. GO-CC analysis shows that the major enriched DEG contained cellular components are the nucleus, intracellular membrane-bound organelle, azurophil granule membrane, organelle outer membrane, azurophil granule, nuclear inner membrane, secretory granule membrane phosphatidylinositol 3-kinase complex of class I, mitochondrial outer membrane, cyclin/CDK positive transcription elongation factor complex, etc. Specific developmental disorder, a developmental disorder of mental health, intracellular disability are associated with those common DEGs. By analyzing the KEGG pathways detains, the enriched pathways are related to growth hormone synthesis, secretion, and absorption, signaling pathways that regulating the pluripotency of stem cells, Cellular senescence, longevity regulating pathway, cholinergic synapse, Kapos I sarcomaassociated herpesvirus infection, estrogen signaling pathway, human T cell leukemia virus 1 infection, human cytomegalovirus infection, PD-L1 exp[ression and PD-1 checkpoint pathway in cancer.

Amigdala, Dendritic cells, peripheral blood are some of the tissue sights where the expression of these DEGs is finely observed.


(b)

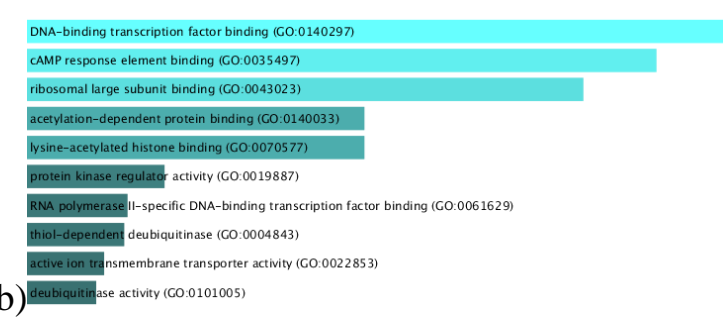

(d)

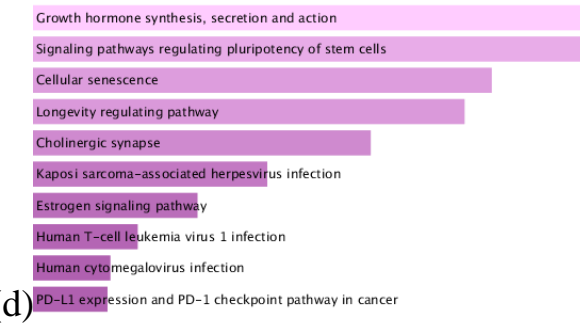

Fig: 6; The GO and KEGG pathways enrichment analysis using Enricher. (a) Top 10 enriched biological processes, $\mathrm{X}$-axis denotes the number of genes and the $\mathrm{y}$-axis shows biological processes (b) Top 10 enriched molecular functions where $\mathrm{X}$-axis denotes the number of genes and the $\mathrm{y}$-axis represents functions. (c) Top 10 enriched cellular components in DEGs, X-axis denotes the number of genes and the y-axis shows cellular components. (d) Top 10 enriched KEGG pathways, X-axis denotes the number of genes and the y-axis represents the pathways.

\section{Conclusion}

Individual study of each disease is done previously but a significant combined study of PD, MS, and HD is not done before. Through these studies, it comes to notice that the four hub genes are common in all the datasets of these diseases are also very common in individual neurodegenerative disorders and a variety of cancers and they are PIK3CA, KRAS, CREB1, JAK2. There might be some possibility that any of those genes could be a drug target. So, further study is necessary for finding a drug target and drug design by computational methods. 


\section{References}

Bender, R. H. F., Haigis, K. M., \& Gutmann, D. H. (2015). Activated K-Ras, But Not H-Ras or NRas, Regulates Brain Neural Stem Cell Proliferation in a Raf/Rb-Dependent Manner. Stem Cells (Dayton, Ohio), 33(6), 1998-2010. https://doi.org/10.1002/stem.1990

Billot, S., Kouroupi, E. G., Le Guilloux, J., Cassinat, B., Jardin, C., Laperche, T., Fenaux, P., Carpentier, A. F., \& Kiladjian, J.-J. (2011). Neurological disorders in essential thrombocythemia. Haematologica, 96(12), 1866-1869. https://doi.org/10.3324/haematol.2011.050005

Clough, E., \& Barrett, T. (2016). The Gene Expression Omnibus database. Methods in Molecular Biology (Clifton, N.J.), 1418, 93-110. https://doi.org/10.1007/978-1-4939-3578-9_5

Enrichr: A comprehensive gene set enrichment analysis web server 2016 update. (n.d.). Retrieved September 22, 2021, from https://www.ncbi.nlm.nih.gov/pmc/articles/PMC4987924/

Farztdinov, V., \& McDyer, F. (2012). Distributional fold change test - a statistical approach for detecting differential expression in microarray experiments. Algorithms for Molecular Biology: AMB, 7, 29. https://doi.org/10.1186/1748-7188-7-29

Fivaz, M., \& Meyer, T. (2005). Reversible intracellular translocation of KRas but not HRas in hippocampal neurons regulated by Ca2+/calmodulin. The Journal of Cell Biology, 170, 429441. https://doi.org/10.1083/jcb.200409157

Ghaddar, N., Wang, S., Woodvine, B., Krishnamoorthy, J., van Hoef, V., Darini, C., Kazimierczak, U., Ah-son, N., Popper, H., Johnson, M., Officer, L., Teodósio, A., Broggini, M., Mann, K. K., Hatzoglou, M., Topisirovic, I., Larsson, O., Le Quesne, J., \& Koromilas, A. E. (2021). The integrated stress response is tumorigenic and constitutes a therapeutic liability in KRASdriven lung cancer. Nature Communications, 12(1), 4651. https://doi.org/10.1038/s41467$021-24661-0$

Jin, C., Pu, J., Zhou, Z., Chen, X., Wu, J., \& Zhang, B. (2020). Rapidly progressive cognitive impairment: An unusual presentation of cerebral venous thrombosis caused by JAK2 V617F- 
positive primary myelofibrosis: A case report. Medicine, 99(34), e21757.

https://doi.org/10.1097/MD.0000000000021757

Kohl, M., Wiese, S., \& Warscheid, B. (2011). Cytoscape: Software for visualization and analysis of biological networks. Methods in Molecular Biology (Clifton, N.J.), 696, 291-303. https://doi.org/10.1007/978-1-60761-987-1_18

Lei, Y., Yu, D., Bin, Z., \& Yang, Y. (2017). Interactive K-Means Clustering Method Based on User Behavior for Different Analysis Target in Medicine. Computational and Mathematical Methods in Medicine, 2017, 4915828. https://doi.org/10.1155/2017/4915828

Li, Y., Zhang, X., Cui, L., Chen, R., Zhang, Y., Zhang, C., Zhu, X., He, T., Shen, Z., Dong, L., Zhao, J., Wen, Y., Zheng, X., \& Li, P. (2017). Salvianolic acids enhance cerebral angiogenesis and neurological recovery by activating JAK2/STAT3 signaling pathway after ischemic stroke in mice. Journal of Neurochemistry, 143(1), 87-99. https://doi.org/10.1111/jnc.14140

Nahm, F. S. (2017). What the P values really tell us. The Korean Journal of Pain, 30(4), 241-242. https://doi.org/10.3344/kjp.2017.30.4.241

Pathan, M., Keerthikumar, S., Ang, C.-S., Gangoda, L., Quek, C. Y. J., Williamson, N. A., Mouradov, D., Sieber, O. M., Simpson, R. J., Salim, A., Bacic, A., Hill, A. F., Stroud, D. A., Ryan, M. T., Agbinya, J. I., Mariadason, J. M., Burgess, A. W., \& Mathivanan, S. (2015). FunRich: An open access standalone functional enrichment and interaction network analysis tool.

Proteomics, 15(15), 2597-2601. https://doi.org/10.1002/pmic.201400515

Rai, S. N., Dilnashin, H., Birla, H., Singh, S. S., Zahra, W., Rathore, A. S., Singh, B. K., \& Singh, S. P. (2019). The Role of PI3K/Akt and ERK in Neurodegenerative Disorders. Neurotoxicity Research, 35(3), 775-795. https://doi.org/10.1007/s12640-019-0003-y

Romano, M., Sollazzo, D., Trabanelli, S., Barone, M., Polverelli, N., Perricone, M., Forte, D., Luatti, S., Cavo, M., Vianelli, N., Jandus, C., Palandri, F., \& Catani, L. (2017). Mutations in JAK2 and Calreticulin genes are associated with specific alterations of the immune system in myelofibrosis. Oncoimmunology, 6(10), e1345402. https://doi.org/10.1080/2162402X.2017.1345402 
Ryu, H.-H., Kang, M., Hwang, K.-D., Jang, H. B., Kim, S. J., \& Lee, Y.-S. (2020). Neuron typespecific expression of a mutant KRAS impairs hippocampal-dependent learning and memory. Scientific Reports, 10(1), 17730. https://doi.org/10.1038/s41598-020-74610-y

Ryu, M.-J., Liu, Y., Zhong, X., Du, J., Peterson, N., Kong, G., Li, H., Wang, J., Salamat, S., Chang, Q., \& Zhang, J. (2012). Oncogenic Kras Expression in Postmitotic Neurons Leads to S100A8-S100A9 Protein Overexpression and Gliosis. The Journal of Biological Chemistry, 287(27), 22948-22958. https://doi.org/10.1074/jbc.M112.357772

Satriotomo, I., Bowen, K. K., \& Vemuganti, R. (2006). JAK2 and STAT3 activation contributes to neuronal damage following transient focal cerebral ischemia. Journal of Neurochemistry, 98(5), 1353-1368. https://doi.org/10.1111/j.1471-4159.2006.04051.x

Seif, F., Khoshmirsafa, M., Aazami, H., Mohsenzadegan, M., Sedighi, G., \& Bahar, M. (2017). The role of JAK-STAT signaling pathway and its regulators in the fate of T helper cells. Cell Communication and Signaling : CCS, 15, 23. https://doi.org/10.1186/s12964-017-0177-y

Stornetta, R. L., \& Zhu, J. J. (2011). Ras and Rap Signaling in Synaptic Plasticity and Mental Disorders. The Neuroscientist : A Review Journal Bringing Neurobiology, Neurology and Psychiatry, 17(1), 54-78. https://doi.org/10.1177/1073858410365562

Trifan, G., Shafi, N., \& Testai, F. D. (2018). Implications of Janus Kinase 2 Mutation in Embolic Stroke of Unknown Source. Journal of Stroke and Cerebrovascular Diseases: The Official Journal of National Stroke Association, 27(10), 2572-2578. https://doi.org/10.1016/j.jstrokecerebrovasdis.2018.05.052

von Mering, C., Huynen, M., Jaeggi, D., Schmidt, S., Bork, P., \& Snel, B. (2003). STRING: A database of predicted functional associations between proteins. Nucleic Acids Research, 31(1), 258-261. https://doi.org/10.1093/nar/gkg034

Warde-Farley, D., Donaldson, S. L., Comes, O., Zuberi, K., Badrawi, R., Chao, P., Franz, M., Grouios, C., Kazi, F., Lopes, C. T., Maitland, A., Mostafavi, S., Montojo, J., Shao, Q., Wright, G., Bader, G. D., \& Morris, Q. (2010). The GeneMANIA prediction server: Biological network integration for gene prioritization and predicting gene function. Nucleic Acids Research, 38(Web Server issue), W214-W220. https://doi.org/10.1093/nar/gkq537 
Xu, F., Na, L., Li, Y., \& Chen, L. (2020). Roles of the PI3K/AKT/mTOR signalling pathways in neurodegenerative diseases and tumours. Cell \& Bioscience, $10,54$.

https://doi.org/10.1186/s13578-020-00416-0

Yasuda, M., Nagappan-Chettiar, S., Johnson-Venkatesh, E. M., \& Umemori, H. (2021). An activitydependent determinant of synapse elimination in the mammalian brain. Neuron, 109(8), 13331349.e6. https://doi.org/10.1016/j.neuron.2021.03.006

王梦华, 卢均坤. PI3K/Akt信号通路及其抑制剂的研究进展 [J]. 医学信息, 2018, 031(010):34-36.

Doi: CNKI:SUN:YXXX.0.2018-10-011. [Wang MH and Lu JK. Research progress of PI3K/Akt signaling pathway and its inhibitors. Med Inf 2018;31(10): 34-36.]. (n.d.). 


\section{GSE1767, selected samples}






\section{GSE19587}

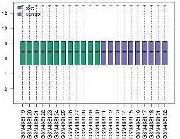




\section{GSE 38010}

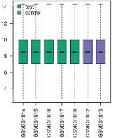




\section{GSE1767 HD}

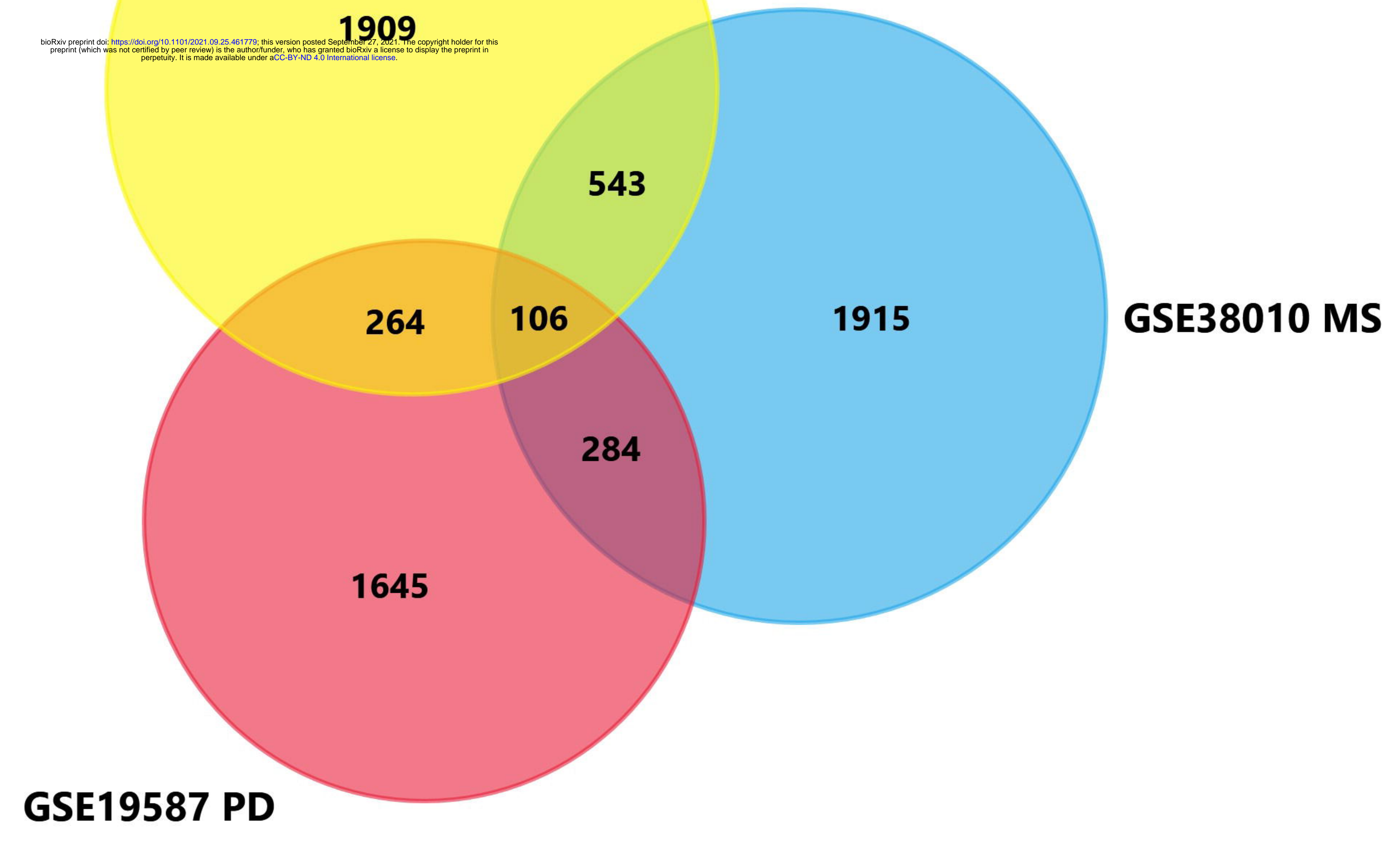




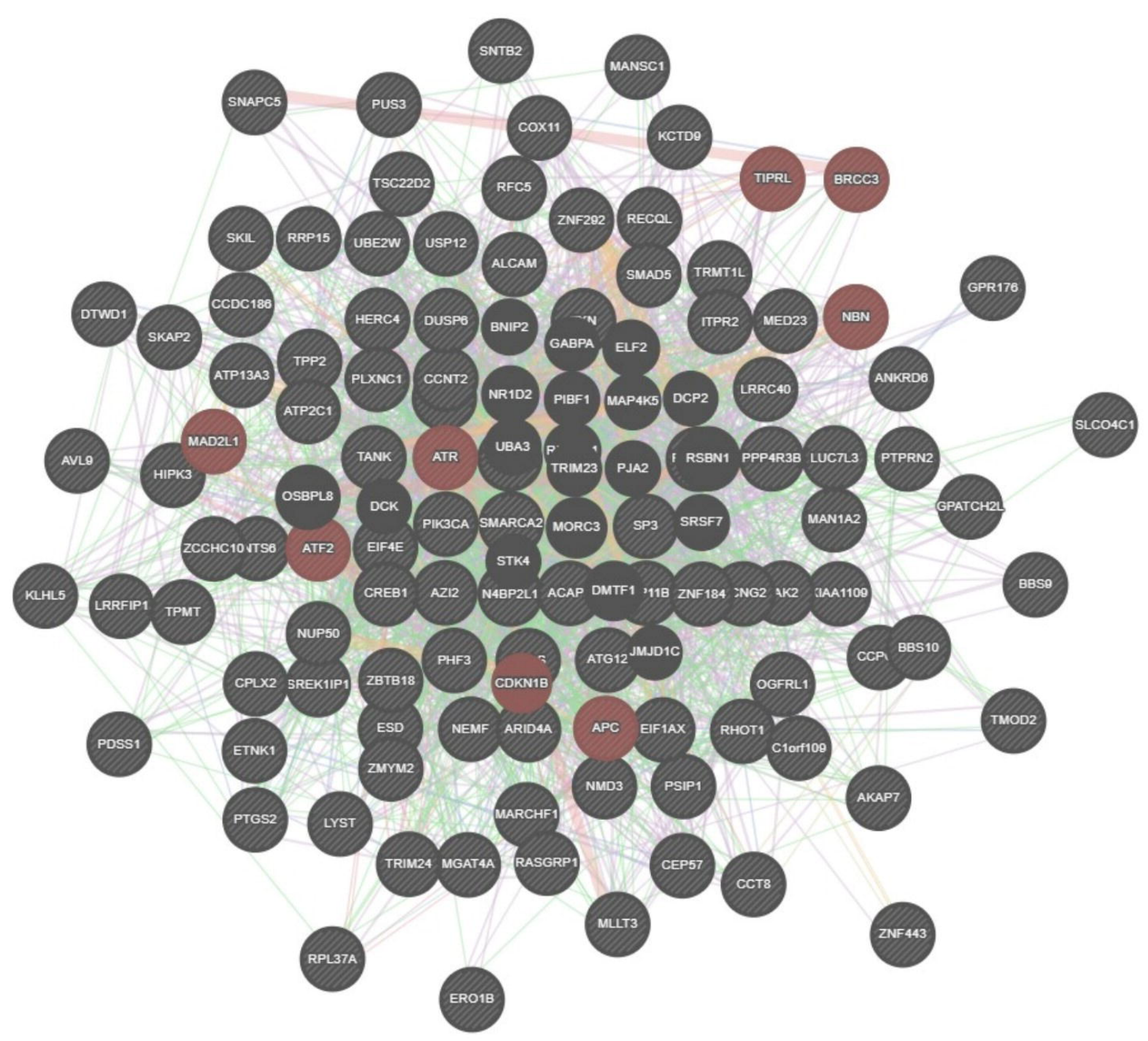

\section{Networks}

1 Co-expression

1 Genetic Interactions

- Physical Interactions

11 Predicted

Co-localization

1 Pathway

1 Shared protein domains

\section{Functions}

- cell cycle checkpoint 












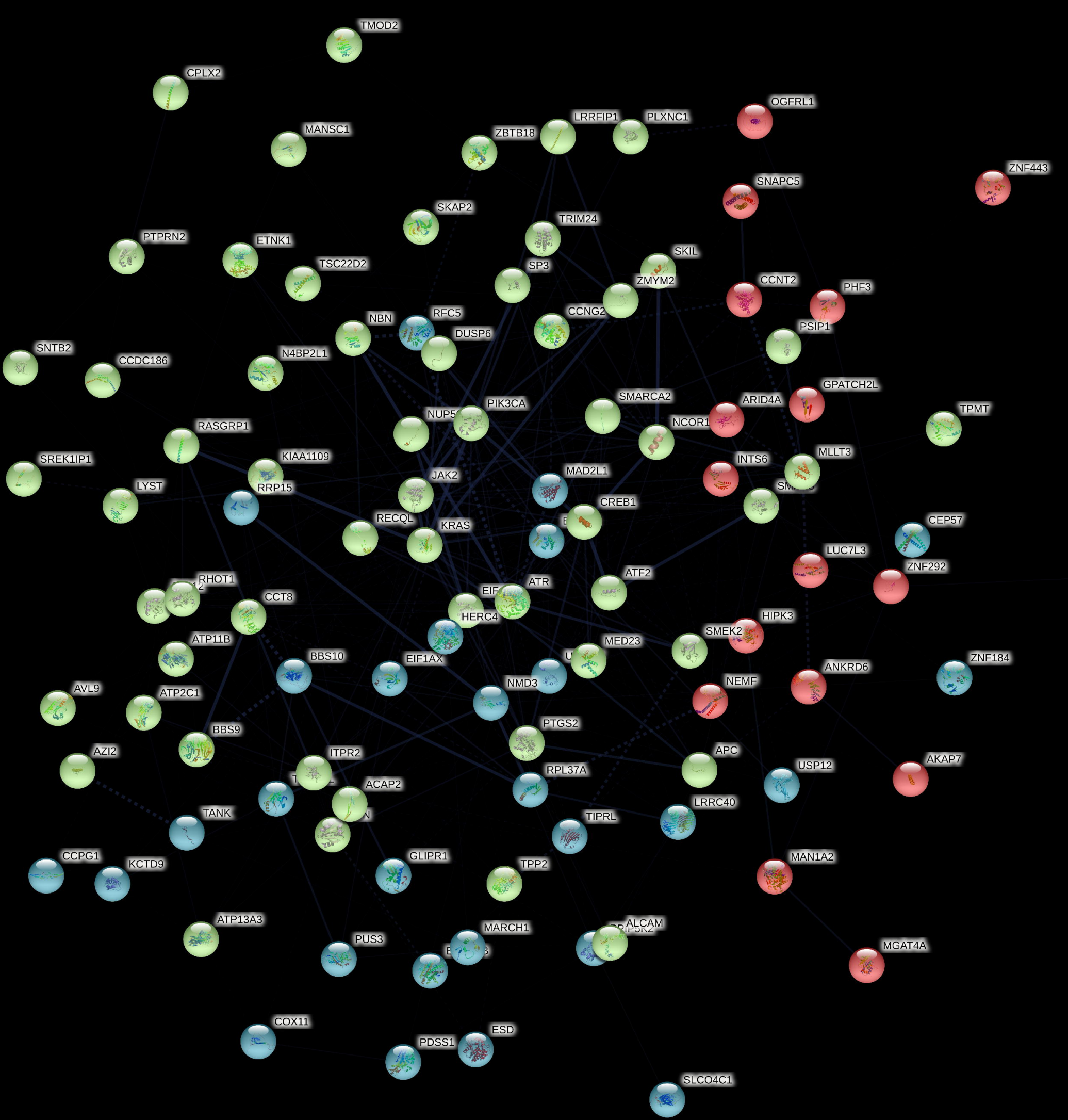










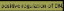

X-dyannaratismig 


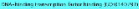



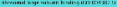

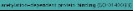

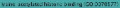

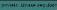

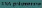

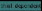

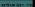

antisinta 


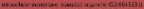

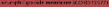

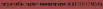

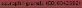

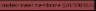

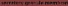

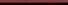

variwitial

trinimitis

thes 


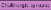

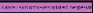

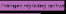

Harcit _.III

itirancsit

$7 \mathrm{nat}$ it most 